\title{
Continuing Professional Development
}

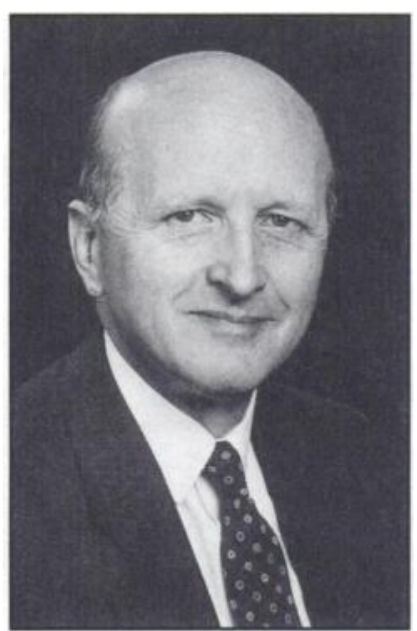

Professor Gethin Morgan
Soon after I retired from my clinical academic post I agreed to become Director of Continuing Professional Development (CPD) for a period of two years, in the hope that I might be able to play a part in ensuring that it becomes firmly established and accepted by psychiatrists as a whole. Having now completed one year as Director, it is gratifying to find the scheme accepted by so many. Nevertheless, I need

to discuss what is perhaps the most pressing of all problems which I face. It concerns the various difficulties which have impeded full recruitment into the scheme.

There is a groundswell of public opinion and expectation, which none can gainsay, that the competence of all clinicians should be regularly reappraised during the time they hold clinical responsibility for patient care. This is in line with developments worldwide, which also concern many other professions, not merely medicine. We may feel doubt about the feasibility of this, especially in a subject such as ours in which a significant number of posts remain unfilled and the size of the clinical work force is large. Public opinion nevertheless demands that the problem be addressed both effectively and expeditiously.

For the moment we have the opportunity to devise a process of self-regulation through CPD. It is of the utmost importance that we set up a system which is accepted by all relevant clinicians. What has surprised me during my first year as Director is the degree of resistance shown by some clinicians to becoming involved. A crucial element in measuring the effectiveness of CPD will be the proportion of clinicians participating in it. Lack of support might mean that should obligatory regular formal reassessment of clinical competence become a reality, an alternative form of reappraisal is more likely to be imposed on us from without, according to rules set by others. Surely it is better to help mould our own scheme, and it is only by having the benefit of advice from participating clinicians that we can have any hope of devising one that wins universal acceptance. Given this overall scenario, it becomes urgently necessary to debate the reasons why some clinicians appear reluctant to register for CPD. Let me set out those which are most often drawn to my attention.

Some maintain that they have always kept upto-date, and so question the need to check up on what they do. This is understandable but times change, and we cannot ignore increasing demands that we should monitor formally the degree to which we remain up-to-date in what we profess. Others say that CPD is too expensive. We are indeed looking at ways of developing relevant educational activities increasingly at local and regional level, thereby reducing the cost for participants both in terms of time and money. It needs to be acknowledged though that the recommended programme set out for CPD represents a carefully considered view on what is needed in order to keep up-to-date: the expense involved existed before CPD arrived on the scene, and has not been invented by the programme itself. The journal Advances in Psychiatric Treatment (the subscription for which is included in our overall CPD fee) is evolving rapidly and in particular is widening its cover of speciality topics. Its immediate relevance to day-to-day clinical work is already widely appreciated, and I believe it deserves our support at this early stage in its development. Yet others see our scheme as unduly complex. Yet apart from the reading element, our criteria are not really any different from those of other colleges: attendance at meetings involves 50 hours annually, an average of one hour each week. The problem of obtaining study leave seems to be a further obstacle for some clinicians. Yet National Health Service trusts which fail to make adequate provision for this need to be challenged, and surely they are more likely to cooperate in the context of a CPD programme. Some specialist groups feel that CPD is dominated unduly by general psychiatrists. That is not true, as careful scrutiny of the CPD Committee membership will reveal and as the whole programme develops, it should become increasingly sensitive to all specialist needs. There seems to be much division of opinion about whether or not CPD should be mandatory. It should be clear that our College recommends its CPD scheme to all clinicians who assume responsibility for the care of psychiatric patients. Yet we have attached great importance to winning the hearts and minds of all clinicians 
so that they willingly become involved. Other colleges assume that all clinicians, as a matter of course, involve themselves in Continuing Medical Education (CME) (CPD). This is a subtle difference, but for them the question of choice does not then arise, and I am not aware of much dissent. Some psychiatrists believe that other colleges do not charge for CME (CPD). Yet any such scheme inevitably involves cost, whether this is absorbed into a general membership subscription or charged as a separate fee, as in the case of psychiatry. The Royal College of Obstetricians and Gynaecolo-gists intends in due course to publish a so called White List of clinicians who have completed its CME programme. I do wonder, in that event, how psychiatrists will fare when the searchlight of public scrutiny will inevitably in turn become focused on us.

It would be splendid if during my second year as Director of CPD I could find myself less involved in trying to persuade clinicians to join CPD, and so be able to devote more time to developing and evaluating the scheme further. The most reliable way to guide me in this challenging task is to participate and thereby provide me with advice based on first-hand involvement in it.

Gethin Morgan, Director of CPD, Royal College of Psychiatrists

\section{Approved nominations to the Fellowship and Membership under Bye-Law III 2 (ii)}

It was agreed that the following candidates should receive the Fellowship:

Dr A. J. Abraham, Dr I. K. J. Al-Adhmawi, Dr M. S. Alexander, Dr A. A. Al-Husaini, Dr M. D. Alldrick, Dr Z. Atakan, Dr P. G. Baines, Dr R. W. K. Bamber, Dr J. C. Barnes, Dr D. J. Bevington, Dr M. R. Bhatti, Dr J. Bird, Dr N. R. Bishay, Dr J. P. Boakes, Dr M. J. Bober, Dr D. M. Bowker, Dr S. R. Britten, Dr J. M. Brockington, Dr B. J. Brockman, Dr D. S. Brooks, Dr S. W. Brown, Dr I. Cariapa, Dr H. R. Cattell, Dr A. K. Chaudhary, Dr G. L. Christie, Dr S. Y. Chung, Dr D. J. Clarke, Dr M. J. ClarkeFinnegan, Dr P. J. Connelly, Dr T. H. Corn, Dr J. Dalton, Dr A. S. David, Dr S. Deb, Dr M. Devakumar, Dr N. M. Devaney, Dr F. I. S. De-Zulueta, Dr D. C. Drummond, Dr J.W. Eastgate, Dr C. Feinmann, Dr F. M. Z. Flynn. Dr M. F. Ford, Dr D. P. Forster, Dr J. Freedman, Dr R. C. S. Furlong, Dr K. George, Dr M. Gilmore-McInerney, Dr W. R. Guirguis, Dr V. J. Harris, Dr T. M. Harrison, Dr P. E. HarrisonRead, Dr P. Haydn-Smith, Dr N. L. Holden, Dr W. Y. C. Hung, Dr M. F. Hussain, Dr R. A. Jackson, Dr A. Janca, Dr M. M. Jilani, Dr D. M.
Jones, Dr E. M. Jones, Dr S. Joseph, Dr E. M. Joyce, Dr A. Kearns, Dr D. D. Kohen, Dr B. W. K. Lau, Dr A. S. Lee, Professor G. H. Lewis, Dr S. N. Mahapatra, Dr J. A. Marks, Dr J. P. McKeon, Dr S. Moorey, Dr J. D. Mumford, Dr E. D. O'Callaghan, Dr D. Pariente, Dr J. K. Pasterski, Dr R. C. Peveler, Dr M. P. Philpot, Dr M. J. H. Qureshi, Dr S. Rajkumar, Dr A. J. Ramirez, Wing Cdr G. E. Reid, Dr A. Roy, Dr M. Roy, Dr D. T. Selvarajah, Dr M. R. Shah, Dr P. J. Shoenberg, Dr A. O. Sirag, Dr J. M. A. Smithies, Dr N. J. Suffling, Dr A. F. S. Tanaghow, Dr R. I. L. Tillett, Dr P. M. Trotter, Dr D. Turkington, Dr J. Walshe, Dr P. E. Watson, Dr A. J. Winbow, Dr A. D. Wolhuter, Dr G. K. K. Yu, Dr A. R. Zachary.

It was agreed that the following should be awarded Membership under Bye-Law III 2(ii):

Professor M. Hussain, Dr J. Maratos.

It was agreed that Dr A. A. Voloshanovich should become a Member under Bye-Law III 2 (ii) and at the same time receive the Fellowship of the College. 